\title{
Bdnf Deletion or TrkB Impairment in Amygdala Inhibits Both Appetitive and Aversive Learning
}

\author{
Scott A. Heldt, ${ }^{1 \star}$ Kelsey Zimmermann, ${ }^{2 \star}$ Kathryn Parker, ${ }^{2}$ Meriem Gaval, ${ }^{2}$ and Kerry J. Ressler ${ }^{2,3}$ \\ ${ }^{1}$ Department of Anatomy and Neurobiology, University of Tennessee Health Science Center, Memphis, Tennessee 38163, ${ }^{2}$ Department of Psychiatry and \\ Behavioral Sciences, Yerkes National Primate Research Center, Emory University, Atlanta, Georgia 30329, and ${ }^{3}$ Howard Hughes Medical Institute, Chevy \\ Chase, Maryland 20815
}

\begin{abstract}
Brain-derived neurotrophic factor (BDNF) is known to have an integral role in establishing stable memories after learning events. The neuroplasticity induced by Pavlovian fear conditioning has likewise been shown to rely on interactions between BDNF and its principal receptor, tyrosine kinase receptor $\mathrm{B}(\operatorname{Trk} \mathrm{B})$, in the amygdala after training. Although the necessity of amygdala $b d n f$ expression and Trk $\mathrm{B}$ activation for associative learning within aversive contexts has been explored, it is unclear to what extent this interaction is involved in appetitive learning. It is also unclear whether the noted increases in amygdala BDNF after fear conditioning are due to local gene transcription and translation or anterograde transmission from cortical regions. To address both of these questions, we used two lentiviral approaches in mice, using both fear conditioning and cocaine-conditioned place preference (CPP), during acquisition and extinction. First, we decreased expression of $b d n f$ mRNA in the amygdala of homozygous floxed mice with a Cre-expressing virus. In a second set of studies, we infused a virus that expressed a dominant-negative TrkB isoform into the same region. These approaches significantly impaired consolidation of fear conditioning and cocaine-CPP, as well as extinction of CPP. Together, these data suggest that BDNF-TrkB signaling is critical for amygdala-dependent learning of both appetitive and aversive emotional memories.
\end{abstract}

Key words: BDNF; TrkB; amygdala; learning

\section{Introduction}

Brain-derived neurotrophic factor (BDNF) has a well-established role in synaptic plasticity within the context of long-term potentiation (LTP) in the adult CNS (Korte et al., 1995; Pang et al., 2004; Bramham and Messaoudi, 2005). In addition to its demonstrated role in hippocampal-dependent learning, interest in the influence of BDNF and its primary receptor, tyrosine kinase receptor B (TrkB), in amygdala-dependent learning has also grown rapidly in recent years. Cell bodies in the basolateral amygdala (BLA) strongly express $b d n f$ mRNA, and the $\operatorname{TrkB}$ receptor is expressed throughout the amygdala, including the BLA and the central nucleus (CeA) (Krause et al., 2008). The BLA is known to facilitate the acquisition and consolidation of appetitive and aversive learning events, and recent studies have shown that $b d n f$ mRNA is significantly upregulated in this region of the amygdala

Received Aug. 25, 2012; revised Dec. 29, 2013; accepted Dec. 30, 2013.

Author contributions: S.A.H. and K.J.R. designed research; S.A.H., K.Z., K.P., and M.G. performed research; K.J.R. contributed unpublished reagents/analytic tools; S.A.H., K.Z., K.P., M.G., and K.J.R. analyzed data; S.A.H., K.Z., and K.J.R. wrote the paper.

This work was supported by National Institutes of Health Grants R01DA01962 and RC1MH088467, the Center for Behavioral Neuroscience (National Science Foundation agreement IBN-987675), the Burroughs Wellcome Fund, and a National Institutes of Health/National Center for Research Resources base Grant P51RR000165 to Yerkes National Primate Research Center.

The authors declare no competing financial interests.

*S.H. and K.Z. contributed equally to this work.

Correspondence should be addressed to Dr. Kerry J. Ressler, Department of Psychiatry and Behavioral Sciences, Yerkes National Primate Research Center, Emory University, Atlanta, GA 30329. E-mail: kressle@emory.edu.

DOI:10.1523/JNEUROSCI.4085-12.2014

Copyright $\odot 2014$ the authors $\quad 0270-6474 / 14 / 342444-07 \$ 15.00 / 0$ following Pavlovian fear conditioning (Rattiner et al., 2004; Ou and Gean, 2006).

The role of the BLA in forming associations between conditioned (CS) and unconditioned (US) stimuli has been extensively studied, and the neurocircuitry involved in amygdala-dependent learning is well defined (Davis, 1992; Fanselow and LeDoux, 1999). Amygdala LTP is induced by fear conditioning, and this plasticity supports the acquisition, consolidation, and expression of aversive associative memories (Rogan et al., 1997; Goosens and Maren, 2002). Furthermore, neural plasticity in the amygdala has been shown to be dependent on BDNF (Rattiner et al., 2005; Cowansage et al., 2010), and point mutations at the primary TrkB phosphorylation sites can alter acquisition and consolidation of fear learning as well as synaptic plasticity (Musumeci et al., 2009). Others have found that local infusion of a TrkB antagonist in the amygdala inhibits fear consolidation in rats (Rattiner et al., 2004) and that in vitro application of either BDNF or 7,8-dihydroxyflavone, another TrkB agonist, lowers the threshold for LTP induction in the BLA (Li et al., 2011, Meis et al., 2012).

Despite ample evidence supporting the necessity of amygdala BDNF-TrkB interactions for the stable formation of fear memories, there is a notable paucity of data addressing the role of this local neurotrophic activity in other forms of amygdala-dependent learning. In addition to supporting stimulus-response learning in aversive contexts, the BLA is also integrally involved in appetitive learning (Everitt et al., 2003). For instance, pretraining excitotoxic lesions of the BLA impair the acquisition of cocaine-conditioned place preference $(\mathrm{CPP})$, whereas post-training ablation at the same 

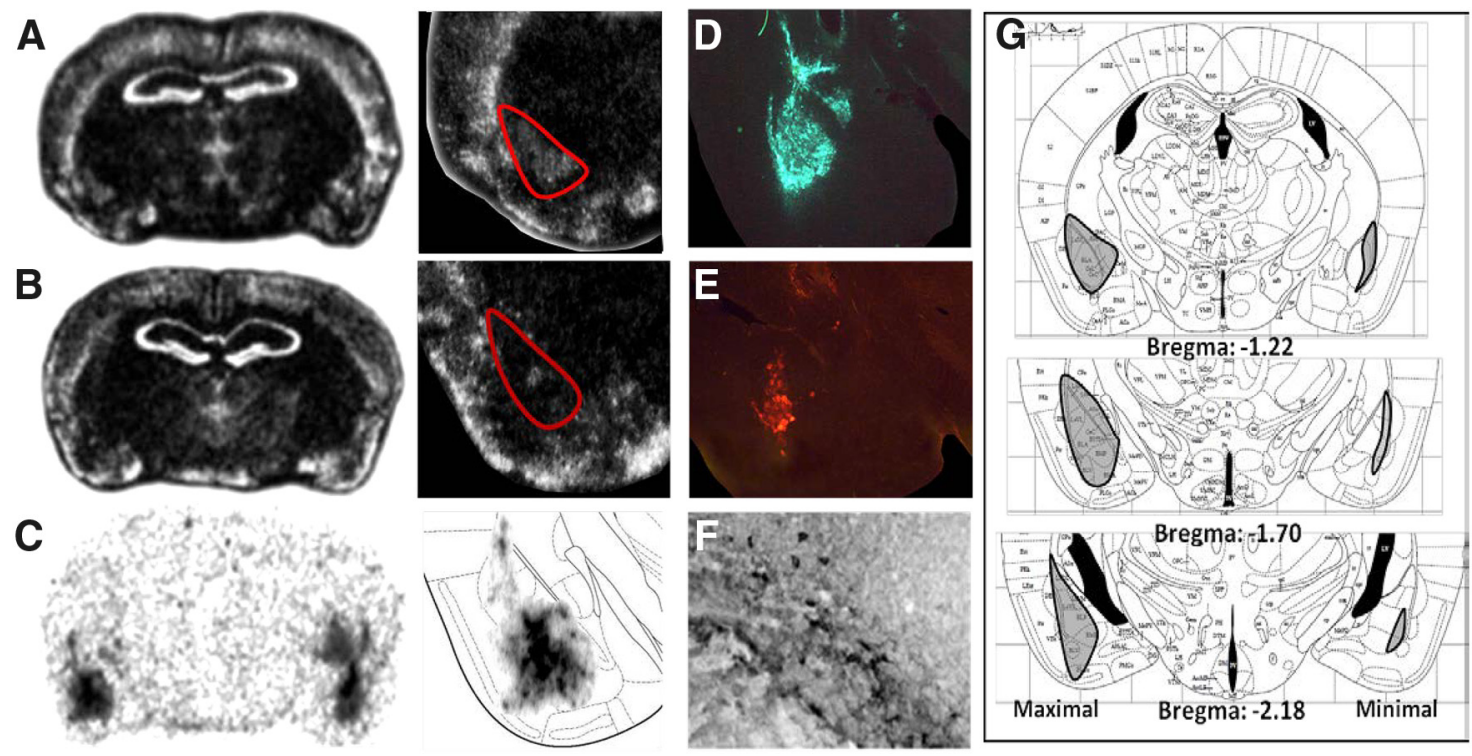

Figure 1. Site-specific $B d n f$ knockdown and TrkB dominant-negative inhibition with lentiviral vector approaches. $A$, Qualitative image showing $B d n f$ in situ hybridization of the amygdala after LV-GFP injection or (B) after LV-Cre injection. C, Qualitative image showing Cre-recombinase in situ hybridization of the amygdala after LV-Cre injection. D, Lentiviral infection with LV-GFP into amygdala $(4 \times)$. E, Lentiviral infection with LV-TrkB.t1 into amygdala $(4 \times)$, visualized with an anti-HA antibody. $\boldsymbol{F}$, LV-TrkB.t1 visualized with an anti-HA antibody and revealed by 3,3' diaminobenzidine (DAB) (20×).G, Infusion maps, drawn upon Paxinos and Franklin (2001) Mouse Atlas Diagrams, for the maximal (left) versus minimal (right) extent of LV-Trkb.t1 viral infusions. The actual infusions were bilateral, with no noticeable difference in left versus right infusion volume.

site impairs extinction of the task (Fuchs et al., 2002); these data strongly support a regulatory function of the BLA in incentivebased memory formation. Other research has also implicated BDNF in drug-seeking behavior ( $\mathrm{Lu}$ et al., 2004), making the contribution of amygdala BDNF to cocaine-based stimulusoutcome learning a promising area of potential study. The following experiments demonstrate the following: (1) both knockdown of the $b d n f$ gene and inhibition of the TrkB receptor within the amygdala impair consolidation of associative memories; and (2) these manipulations similarly affect learning in both aversive and appetitive paradigms.

\section{Materials and Methods \\ Animals}

All mice were housed in standard group cages and given ad libitum access to both food and water. Ambient temperature remained at $20^{\circ} \mathrm{C}$ throughout the experiment. Experiments were performed during the light portion of a $12 \mathrm{~h}$ light/dark cycle. All experiments were approved by Emory University Institutional Review Board following Institutional Animal Care and Use Committee standards with accordance to the Yerkes Primate Research Center regulations.

$L V$-Cre. Homozygous $b d n f$-floxed mice were originally obtained from The Jackson Laboratory (Bdnftm3Jae/J) and bred within our animal facility. These mice possessed loxP sites both upstream and downstream of exon 5 of the $B d n f$ gene. This strain was originated and maintained on a mixed B6, 129S4, BALB/c background and did not display any gross physical or behavioral abnormalities. Experiments were conducted on male mice between 5 and 10 weeks of age.

$L V$-TrkB.t1. Adult (14-17 weeks old) male C57BL/6 mice weighing 20-30 g (The Jackson Laboratory) were used in these experiments. No important baseline differences were seen in the strains of mice C57BL/6 versus mixed strain used for the LV-TrkB.t1 versus LV-Cre lines, but for these reasons, littermates were always used as within experiment controls.

\section{Lentiviral vectors}

$L V$-GFP. Viral vectors were derived from the HIV-based lentivirus backbone $\mathrm{pLV}$-CMV-GFP-U3Nhe, which allows for virally mediated expres- sion of GFP driven by a CMV promoter. Infected neurons remain intact and express the fluorescent marker.

$L V$-Cre. We created a Cre-recombinase expressing viral vector (LVCre) by replacing the GFP coding sequence in PLV-CMV-GFP-U3Nhe with the coding sequence for Cre-recombinase. Viral production procedures were described in detail previously (Heldt et al., 2007).

LV-TrkB.t1. Dominant-negative TrkB.t1 is a truncated version of TrkB that binds BDNF but lacks a catalytic, cytoplasmic kinase domain (Haapasalo et al., 2002). Lentiviral TrkB.t1 transfections inhibit BDNF signaling in vivo (Rattiner et al., 2004) and in vitro (Li et al., 1998; Haapasalo et al., 2002; Offenhäuser et al., 2002). The virus was tagged with HA, making it possible to confirm infusion sites.

\section{Surgery}

Mice received bilateral amygdala microinjections of LV-Cre, LVTrkB.t1, or LV-GFP. Mice were anesthetized with a Ketastet $(80 \mathrm{mg} / \mathrm{kg}) /$ Dormitor $(1 \mathrm{mg} / \mathrm{kg})$ solution and then mounted in a stereotaxic apparatus. Small holes were drilled in the skull above the injection sites, and a Hamilton microsyringe was lowered to the following coordinates from bregma: anteroposterior $=-1.4$, mediolateral $= \pm 3.1$, dorsoventral $=-5.0$. A total volume of $1.5 \mu \mathrm{l}$ was administered at a rate of 0.1 $\mu \mathrm{l} / \mathrm{min}(0.2 \mu \mathrm{l} / \mathrm{min}$ for LV-TrkB.t1). The needle remained in place for 10 min after the injection and was removed at a rate of $0.5 \mathrm{~mm} / \mathrm{min}$. The subject's skin was then sewn together using 1.5 metric polyglactin absorbable sutures. After recovery from anesthesia, mice were given a narcotic analgesic, returned to home cages, and monitored daily for $14 \mathrm{~d}$ before testing.

\section{Histology}

$L V$-Cre. Mice were deeply anesthetized, and their brains were rapidly removed and frozen on dry ice. Coronal sections $(20 \mu \mathrm{m})$ were cut on a cryostat, mounted on gelatin-coated slides, and stored at $-80^{\circ} \mathrm{C}$ until processed. In situ hybridization was performed to examine the expression of mRNA as previously described (Ressler et al., 2002).

$L V$-TrkB.t1. After ketamine overdose, animals were perfused intracardially using $4 \%$ paraformaldehyde in $1 \times$ PBS; $55 \mu \mathrm{m}$ sections were taken on a microtome, and sectioned tissue was blocked with $2 \%$ normal goat serum and $1 \%$ BSA in $1 \times \mathrm{PBS}^{+}(0.4 \%$ Triton $\mathrm{X}-100)$ and incubated in a 1:1000 dilution of HA rabbit polyclonal antibody 
(Sigma) overnight at $4^{\circ} \mathrm{C}$. Sections were then washed in $1 \times$ PBS and incubated in a 1:500 dilution of AlexaFluor-594 goat anti-rabbit secondary antibody for $1 \mathrm{~h}$ at room temperature. The sections were mounted and coverslipped.

$L V$-GFP. After ketamine overdose, animals were perfused intracardially using $4 \%$ paraformaldehyde in $1 \times \mathrm{PBS} ; 55 \mu \mathrm{m} \mathrm{sec}-$ tions were taken on a microtome, mounted, coverslipped, and visualized for endogenous GFP fluorescence.

\section{Conditioned place preference}

Apparatus. Three compartment CPP chambers (Med Associates, product MED-CPP-MS) were used for training and testing.

Pretest. All animals were pretested for individual place preference over a $2 \mathrm{~d}$ period. Pretests consisted of placing the subject in the neutral compartment and allowing $20 \mathrm{~min}$ of free access to all chambers. Time spent in each chamber was recorded, and the chamber in which each animal spent the most time was codified as the "preferred side," whereas the opposing chamber was the "nonpreferred side."

Training. Training used a biased design, in which subjects received cocaine pairings on the nonpreferred side. For $3 \mathrm{~d}$, mice received one pairing session in the morning and one in the afternoon (each lasting $30 \mathrm{~min}$ ). Intraperitoneal injections of cocaine hydrochloride (10 $\mathrm{mg} / \mathrm{kg}$, Sigma) were paired with the animal's nonpreferred chamber, whereas sterile $1 \times$ PBS was paired with the preferred chamber. The cocaine pairing was counterbalanced between morning and afternoon to ensure that time of administration did not affect acquisition of CPP.

Testing. Mice were allowed to freely explore all three chambers for $20 \mathrm{~min}$. Time spent in each chamber was recorded.

Extinction testing. The same protocol as the test day was used. Diminished preference for the cocaine-paired chamber following the unreinforced test day was considered extinction learning.
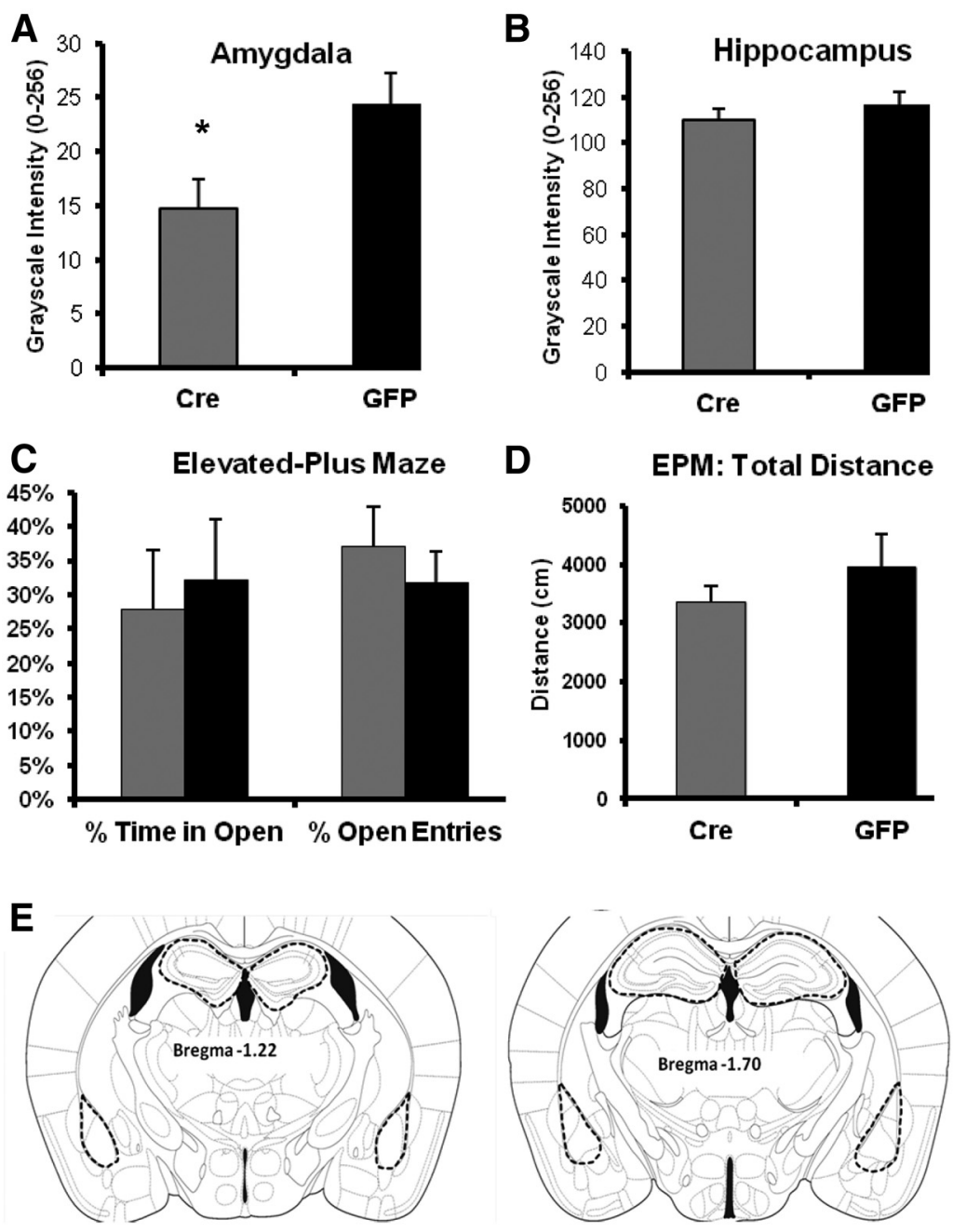

Figure 2. Knockdown of amygdala $B d n f$ is not associated with general anxiety-like effects. Relative $b d n f$ mRNA expression in amygdala $(\boldsymbol{A})$ and CA3 region of dorsal hippocampus $(\boldsymbol{B})$ of mice injected with LV-Cre (Cre) or LV-GFP (GFP) in the amygdala. Bdnf mRNA expression was significantly reduced specifically at the site of infusion $\left(t_{(26)}=2.6, p=0.016\right)$ but was not affected in the noninfused control region ( $p>0.1)$. C, LV-Cre and control LV-GFP mice displayed similar levels of baseline anxiety-like behavior in the elevated plus maze and did not vary in percentage time spent in the open arms $(p>0.1)$ or the percentage of entries into open arms $(p>0.1)$. D, Both LV-Cre and control LV-GFP mice displayed similar levels of motor activity as assessed by total ambulatory distance during EPM testing $(p>0.1)$. E, Masks outlining the hippocampal and amygdala regions of interest used for quantitative analyses of in situ hybridization studies shown at two different anterior-posterior locations. Data are mean \pm SEM. ${ }^{*} p<0.05$.

\section{Fear training and testing}

Fear-potentiated startle (FPS). SR-LAB startle response systems (San Diego Instruments) were used for training and testing. During training, mice were placed in chambers and after 5 min received the first of 10 light + shock trials consisting of a $30 \mathrm{~s}$ CS light coterminating with a $0.5 \mathrm{~s}, 0.6$ $\mathrm{mA}$ footshock. On each of 2 consecutive days after training, fear was assessed in the same context using the FPS paradigm. For each test, mice were presented with 4 startle stimuli at each of three different startle stimulus intensities $(95,105$, and $115 \mathrm{~dB})$. After these initial trials, mice were presented with 4 additional startle-alone trials and 4 light + startle trials at each of the three startle stimulus intensities. A percentage of FPS was computed by dividing the difference between these two trial types by the mean startle amplitude on startle-alone trials: percent FPS $=[[$ (light + startle $)-($ startle-alone) $] /$ startle-alone $)] \times 100$.

\section{Elevated plus maze}

The elevated plus maze consisted of two open arms $(50 \times 6.5 \mathrm{~cm})$ and two closed arms attached to a common central platform $(6.5 \times 6.5 \mathrm{~cm})$ to form a cross. The percentage of open arm entries [open arm/(open + closed arm) entries] and percentage time in open arms [time in open arms/(open + closed arms)] were measured.

\section{Results}

Complementary site-specific Bdnf deletion and TrkB inhibition with lentiviral vector approaches

Although we have previously used the inducible knock-out technique with Cre-expressing lentivirus in several other brain regions (Heldt et al., 2007; Choi et al., 2010), we had not examined the effect of $b d n f$ gene deletion within the amygdala. In these studies, we bilaterally infected the amygdala of homozygous floxed mice with lentivirus expressing Cre recombinase. We then performed behavioral studies followed by in situ hybridization to confirm amygdala-specific deletion. We found significant depletion of $b d n f$ mRNA in the BLA of mice infected with the LV-Cre virus compared with LV-GFP-infected controls (Fig. 1A-C). The regions used for in situ analysis are depicted in Figure $1 G$. Figure $2 A, B$ illustrates quantitative knockdown of $b d n f$ mRNA in amygdala $\left(t_{(26)}=2.6, p=0.016\right)$, but not hippocampus.

We have previously shown that our dominant-negative TrkB virus with a truncated cytoplasmic tail (LV-TrkB.t1) impairs fear 
conditioning and extinction in the rat but that it has no effect on basal measures of anxiety-like behavior (Rattiner et al., 2004; Chhatwal et al., 2006). In the current studies, we verified that we could similarly infect the amygdala with LV-GFP or LV-TrkB.t1 in mice (Fig. $1 D-F$ ). To determine whether amygdala-specific $b d n f$ deletion affects baseline anxiety, we infected $b d n f$-floxed mice bilaterally with LV-Cre or LV-GFP and examined their behavior on the elevated plus maze. We found no differences in time on open arms, percentage of open arm entries, or total distance traveled between these groups (Figs. 2C,D). Notably, we have previously shown that infection with LV-Cre has no behavioral effects on wild-type mice, indicating that our results are not the result of nonspecific effects of the virus (Heldt and Ressler, 2010). These data demonstrate that our inducible lentiviral vector approaches to either knock down $b d n f$ gene expression or to impair TrkB functioning with a dominant-negative isoform are region-specific and do not affect locomotor behavior or baseline anxiety-like behaviors.

\section{$B d n f$ knockdown in the amygdala impairs FPS}

We next examined whether $b d n f$ knockdown in the amygdala would result in impaired fear conditioning in the same manner as inhibition of amygdala TrkB function (Rattiner et al., 2004). After bilateral amygdala infection, animals were subjected to 10 light-shock pairings. The next $2 \mathrm{~d}$, they were tested for FPS. We found that $b d n f$-floxed mice infected with LV-GFP demonstrated significant post-training FPS (Fig. $3 A$; repeated-measures ANOVA, comparing pre, post 1 , and post 2 percentage FPS within the GFP group, $\left.F_{(2,25)}=5.28, p=0.01\right)$, whereas the mice infected with LV-Cre, with bilateral amygdala $b d n f$ deletion, did not (repeated-measures ANOVA as above, $F_{(2,25)}=$ $2.15, p>0.1$ ). Figure $3 B$ demonstrates the extent of LV-Cre infusion in these animals. These data suggest that BDNF must be produced within the amygdala in order for fear memories to be established.

$B d n f$ knockdown and dominant-negative impairment of TrkB in the amygdala delay place preference and impair extinction In addition to the contribution of amygdala BDNF to fear acquisition and consolidation, we also examined the effect of these manipulations on appetitive learning using CPP. We found that mice with Cre-mediated knockdown of $b d n f$ in the amygdala failed to show significant preference for the cocainepaired chamber over the saline-paired chamber, whereas LVGFP-infected controls formed a robust preference, spending significantly more time in the cocaine-paired chamber (Fig. $4 A, B)$. A mixed-model repeated-measures ANOVA was performed, examining a drug (cocaine vs saline chamber) $\times$ group (Cre vs GFP) interaction. This was significant for the interaction effect $\left(F_{(1,27)}=4.1, p=0.05\right)$. Additionally, when we examined the groups separately, we found no significant difference in the Cre group but a significant effect of preference for the cocaine chamber in the GFP group $\left(F_{(1,14)}=17.0\right.$, $p=0.001)$.

Similarly, mice that received bilateral infusions of the dominant-negative TrkB.tl virus in the amygdala did not demonstrate preference for the cocaine-paired chamber (Fig. $4 C, D$ ). A mixed-model repeated-measures ANOVA was performed, examining a drug (cocaine vs saline chamber) $\times$ group (LVTrkB.tl vs LV-GFP) interaction. We found a trend toward a significant interaction $\left(F_{(1,39)}=1.99\right.$, one-tailed test, $\left.p=0.08\right)$. Post hoc analyses revealed that the LV-GFP animals successfully acquired CPP $\left(t_{(15)}=2.63, p=0.02\right)$, whereas the LV-TrkB.t1
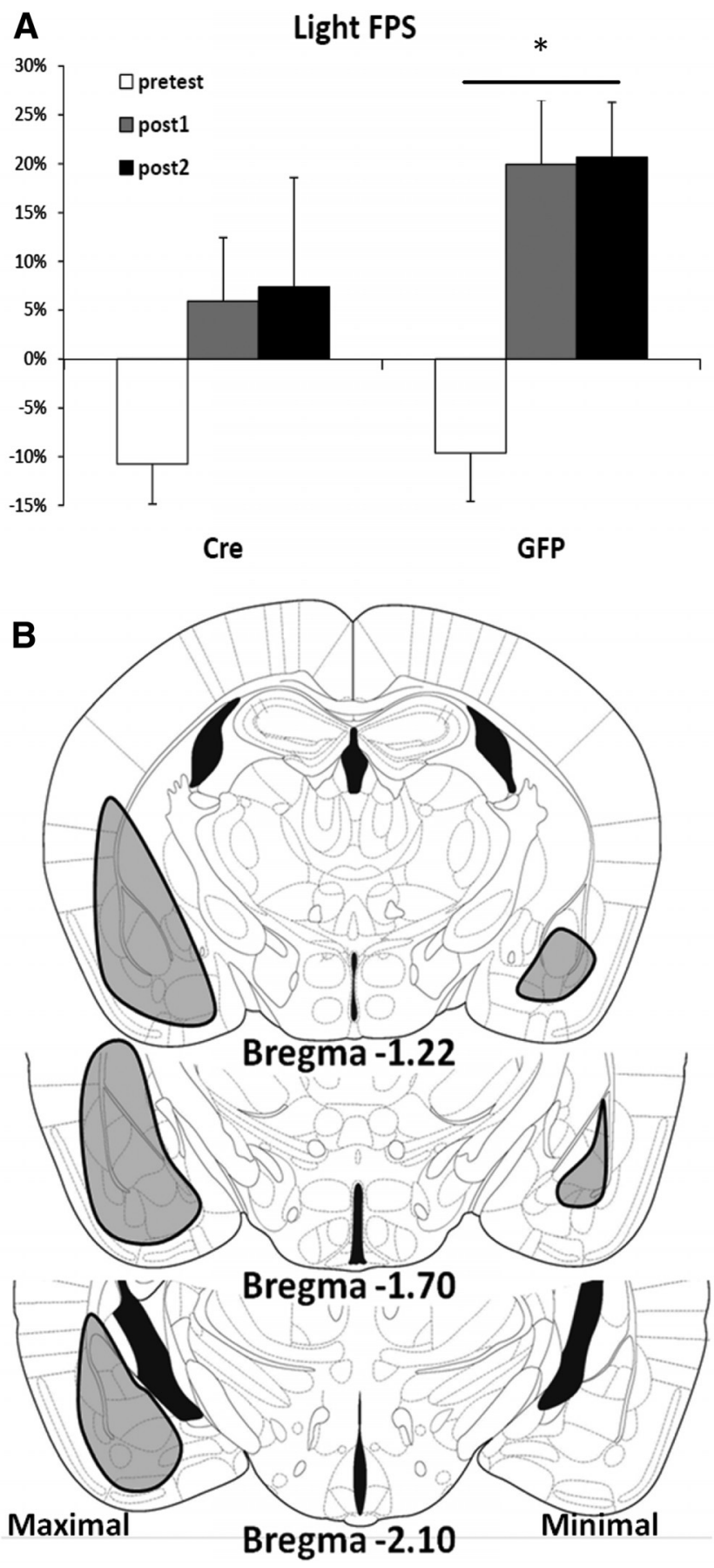

Figure 3. Bdnf knockdown in the amygdala and dominant-negative impairment of TrkB disrupt FPS. A, Percentage FPS is graphed for the pretraining test (pretest) and subsequent post-training tests (post1 and post2). Mice infected with LV-GFP (GFP) demonstrate significant increases in their level of conditioned fear after training as measured with percentage FPS $\left(F_{(2,25)}=5.28, p=0.01\right)$. In contrast, LV-Cre infected mice ( $(r e)$ showed no significant increase in percentage FPS across testing sessions ( $p>0.1)$. $\boldsymbol{B}$, Maximal (left) and minimal (right) spread of LV-Cre infusions are shown, drawn upon Paxinos and Franklin (2001) Mouse Atlas Diagrams. The actual infusions were bilateral, with no noticeable difference in left versus right infusion volume. Data are mean \pm SEM. ${ }^{*} p<0.05$.

animals did not $\left(t_{(16)}=0.96, p=0.35\right)$. Together, these data suggest an influential role for amygdalar BDNF-TrkB interactions in the acquisition of cocaine-CPP.

Finally, these experiments were repeated in an entirely separate cohort of mice to further examine the effect of blocking 
TrkB in amygdala on CPP extinction (Fig. 4E,F). A mixed-model repeatedmeasures ANOVA was performed, examining a drug (cocaine vs saline chamber) $\times$ group (LV-TrkB.t1 vs LVGFP) $\times$ test (post 1 vs post2) interaction. We found a significant chamber $X$ group $\times$ test interaction effect $\left(F_{(1,18)}=\right.$ 3.36 , one-tailed test, $p<0.05$ ). Post hoc analyses revealed that, during Test 1 , both TrkB.t1 and GFP groups demonstrated a significant place preference. However, after extinction of CPP associated with this first test, the GFP group no longer showed a place preference $\left(t_{(9)}=1.07, p=0.3\right)$, whereas the TrkB.t1 group continued to show a difference $\left(t_{(9)}=2.54, p<0.01\right)$, suggesting that appetitive extinction was impaired with this amygdala-TrkB.t1 manipulation.

\section{Discussion}

Synaptic plasticity in the amygdala plays a significant role in encoding representations of both appetitive and aversive learning events. We have demonstrated that either knocking down the expression of $b d n f$ mRNA or sequestering BDNF with an inactive isoform of its principal TrkB receptor significantly impairs the consolidation of both aversive and appetitive conditioning. Bdnf-floxed mice that received bilateral infusions of LV-Cre into the amygdala failed to show fear-potentiated startle to a conditioned stimulus and did not exhibit significant preference for a cocaine-paired chamber over a saline-paired chamber. Likewise, bilateral infusion of a virus expressing the dominant-negative TrkB isoform, TrkB.t1, produced the same deficits in both tasks. Additionally, to complement prior work showing that LV-TrkB.t1 within amygdala impairs extinction of conditioned fear (Chhatwal et al., 2006), we also now show that the same manipulation impairs extinction of the appetitive CPP task. These data suggest that amygdala BDNF is critical for aversive and appetitive learning and that activation of amygdala TrkB receptors similarly enables acquisition and/or consolidation of emotionally salient events.

The promotion of synaptic plasticity (Rattiner et al., 2005; Chhatwal et al., 2006; Musumeci et al., 2009; Cowansage et al., 2010) and LTP (Li et al., 2011) in the amygdala via interaction between BDNF and the TrkB receptor has been shown to facilitate encoding of the CS-US representation during fear conditioning and/or enable effective consolidation of the event. When expression or function of either BDNF or its receptor is impeded in the amygdala, behavioral expression of a fear response to the CS in subsequent tests is significantly blunted, which indicates that training of the CS-US contingency was ineffectual. Inhibition of receptor function alone would not exclude the possibility that plasticity was induced principally by prefrontal cortical re-
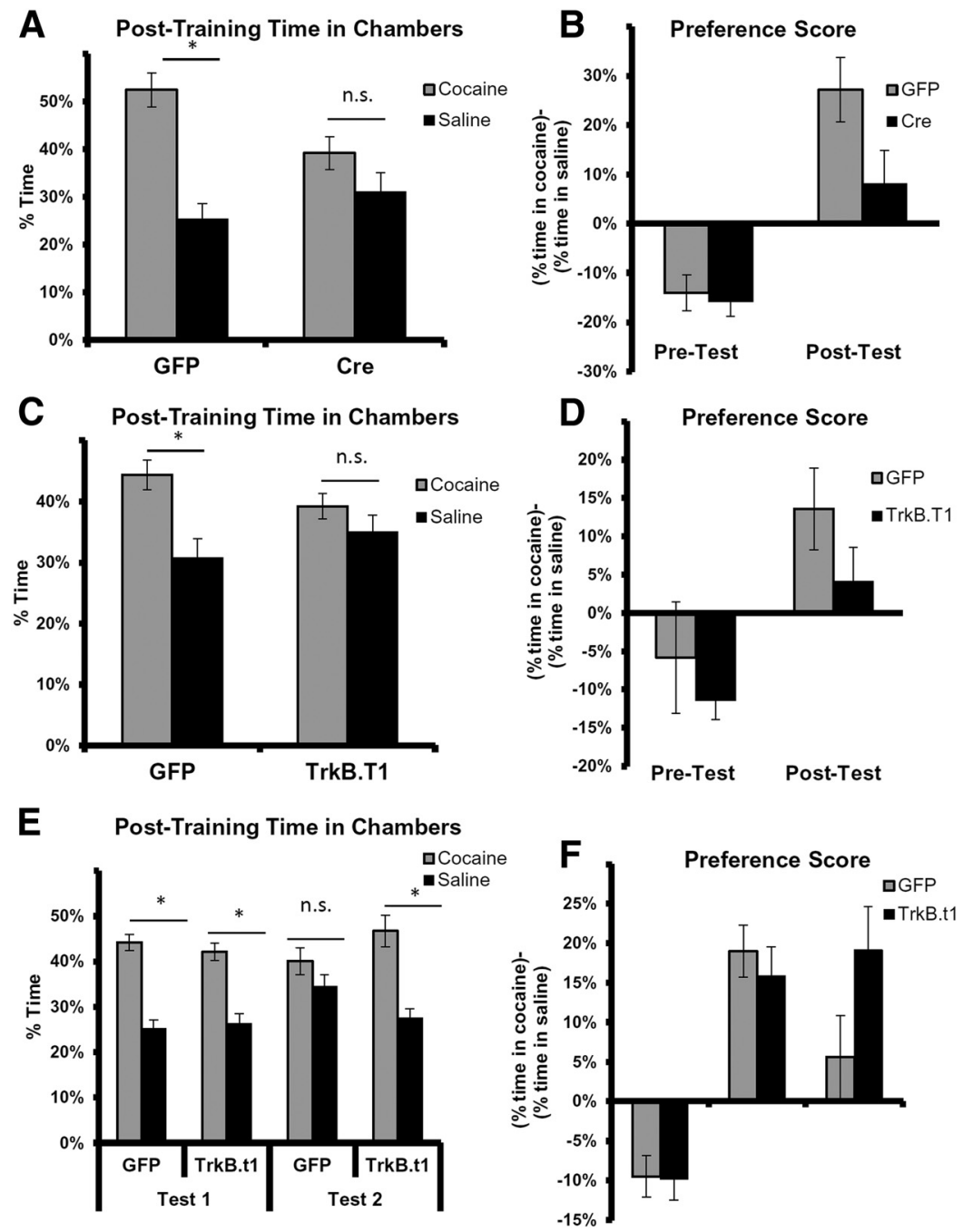

Figure 4. Bdnfknockdown in the amygdala and dominant-negative impairment of TrkB prevent development of preference for a chamber previously paired with cocaine. $\boldsymbol{A}$, LV-GFP mice (GFP) spent significantly more time in the cocaine-paired chamber during post-testing $\left(F_{(1,14)}=17.0, p=0.001\right)$, whereas LV-Cre mice (Cre) did not. $\boldsymbol{B}$, In the post-test, the average LV-Cre group preference score trended lower than the average LV-GFP group score. These results suggest that LV-Cre mice showed less prefermice spent significantly more time in the cocaine-paired chamber during post-testing $\left(F_{(1,15)}=7.0, p=0.019\right)$, whereas mice infected with LV-TrkB.t1 did not $(p>0.1)$. D, 0n the post-test, the average LV-TrkB.t1 group preference score tended lower than oups exhibit preference for cocaine chambers in Test 1, but only the LV-TrkB.t1-infected animals exhibit this preference in Test 2. $\boldsymbol{F}$, This effect is further demonstrated in the relative cocaine preference in pretest, post-test 1 , and post-test 2 . Data are mean \pm SEM. ${ }^{*} p<0.05$. n.s., not significant.

lease of BDNF during acquisition or consolidation. However, when considered alongside the results from local knockdown of the $b d n f$ gene, these data suggest that production of BDNF within the amygdala is also necessary for a lasting memory of the association to be established. Whether BDNF produced within the BLA is acting solely on local TrkB receptors in the BLA and/or central amygdala in a largely isolated amygdalar circuit or being transported to other downstream targets as well is still unknown. In the current experiments, $b d n f$ knockdown in amygdala would affect BDNF release at terminals, whereas TrkB.t1 overexpression would not. It is therefore important to consider that, although the effects of TrkB inhibition are specific to the infected region, knockdown of $b d n f$ in the amygdala potentially affects multiple behaviorally relevant postsynaptic target sites that receive BDNF via transmission from the BLA. 
Although our infusions spanned multiple amygdalar nuclei, $b d n f m R N A$ is absent from the CeA and expression is most prominent in the BLA (Krause et al., 2008). Some, but not all, of our infusions extended beyond the amygdala to surrounding cortical areas that are positive for $b d n f$ mRNA (e.g., endopiriform nulei and, less frequently, the piriform cortex), but infection was not strong in these areas and did not seem to affect behavioral outcomes. We therefore suggest that knockdown of $b d n f$ in the BLA, rather than other amygdalar nuclei or surrounding cortical areas, most likely generated behavioral differences. In contrast, TrkB is present throughout the amygdala and is also known to be expressed in glia (Kumar et al., 1993; Zhou et al., 1993); therefore, we cannot state, based on our data, which region of the amygdala is most reliant on TrkB activation for associative learning or whether expression of the virus in white matter tracts like the external capsule contributed to the behavioral differences.

Despite the opposing valences of fear- and incentive-based learning, there are clear advantages to studying the two motivations in concert. The lateral and basolateral nuclei of the amygdala have long been acknowledged as primary sites of associative learning in fear conditioning, but it is also widely understood that the amygdala codifies information about positively as well as negatively valenced stimuli. What is ostensibly an evolutionary advantage (having one structure that encodes a variety of emotionally disparate events) also potentially represents a risk for developing comorbid pathologies. For instance, in humans, the val66met $B d n f$ gene variant has been associated with increased risk for substance abuse (Cheng et al., 2005) as well as impaired fear extinction (Frielingsdorf et al., 2010; Lonsdorf et al., 2010; Soliman et al., 2010). This same variant has been shown to affect amygdalar activity during emotional memory formation (van Wingen et al., 2010, Soliman et al., 2010) and can also confer a risk for developing disorders that are based upon opposite motivations (i.e., addiction and post-traumatic stress disorder). There are many shared components in the neurocircuitry underlying aversive and appetitive learning, and exploring the extent to which these pathways overlap will permit a more comprehensive approach to studying healthy and maladaptive consolidation processes that are used in forming memories of emotionally relevant events.

\section{References}

Bramham CR, Messaoudi E (2005) BDNF function in adult synaptic plasticity: the synaptic consolidation hypothesis. Prog Neurobiol 76:99-125. CrossRef Medline

Cheng CY, Hong CJ, Yu YW, Chen TJ, Wu HC, Tsai SJ (2005) Brain-derived neurotrophic factor (Val66Met) genetic polymorphism is associated with substance abuse in males. Brain Res Mol Brain Res 140:86-90. CrossRef Medline

Chhatwal JP, Stanek-Rattiner L, Davis M, Ressler KJ (2006) Amygdala BDNF signaling is required for consolidation but not encoding of extinction. Nat Neurosci 9:870-872. CrossRef Medline

Choi DC, Maguschak KA, Ye K, Jang SW, Myers KM, Ressler KJ (2010) Prelimbic cortical BDNF is required for memory of learned fear but not extinction or innate fear. Proc Natl Acad Sci U S A 107:2675-2680. CrossRef Medline

Cowansage KK, LeDoux JE, Monfils MH (2010) Brain-derived neurotrophic factor: a dynamic gatekeeper of neural plasticity. Curr Mol Pharmacol 3:12-29. CrossRef Medline

Davis M (1992) The role of the amygdala in fear and anxiety. Annu Rev Neurosci 15:353-375. CrossRef Medline

Everitt BJ, Cardinal RN, Parkinson JA, Robbins TW (2003) Appetitive behavior: impact of amygdala-dependent mechanisms of emotional learning. Ann N Y Acad Sci 985:233-250. CrossRef Medline

Fanselow MS, LeDoux JE (1999) Why we think plasticity underlying Pav- lovian fear conditioning occurs in the basolateral amygdala. Neuron 23: 229-232. CrossRef Medline

Frielingsdorf H, Bath KG, Soliman F, Difede J, Casey BJ, Lee FS (2010) Variant brain-derived neurotrophic factor Val66Met endophenotypes: implications for posttraumatic stress disorder. Ann N Y Acad Sci 1208: 150-157. CrossRef Medline

Fuchs RA, Weber SM, Rice HJ, Neisewander JL (2002) Effects of excitotoxic lesions of the basolateral amygdala on cocaine-seeking behavior and cocaine conditioned place preference in rats. Brain Res 929:15-25. CrossRef Medline

Goosens KA, Maren S (2002) Long-term potentiation as a substrate for memory: evidence from studies of amygdaloid plasticity and Pavlovian fear conditioning. Hippocampus 12:592-599. CrossRef Medline

Haapasalo A, Sipola I, Larsson K, Akerman KE, Stoilov P, Stamm S, Wong G, Castren E (2002) Regulation of TRKB surface expression by brainderived neurotrophic factor and truncated TRKB isoforms. J Biol Chem 277:43160-43167. CrossRef Medline

Heldt SA, Ressler KJ (2010) Amygdala-specific reduction of alpha1-GABAA receptors disrupts the anticonvulsant, locomotor, and sedative, but not anxiolytic, effects of benzodiazepines in mice. J Neurosci 30:7139-7151. Medline

Heldt SA, Stanek L, Chhatwal JP, Ressler KJ (2007) Hippocampus-specific deletion of BDNF in adult mice impairs spatial memory and extinction of aversive memories. Mol Psychiatry 12:656-670. CrossRef Medline

Korte M, Carroll P, Wolf E, Brem G, Thoenen H, Bonhoeffer T (1995) Hippocampal long-term potentiation is impaired in mice lacking brainderived neurotrophic factor. Proc Natl Acad Sci U S A 92:8856-8860. Medline

Krause S, Schindowski K, Zechel S, von Bohlen und Halbach O (2008) Expression of trkB and trkC receptors and their ligands brain-derived neurotrophic factor and neurotrophin-3 in the murine amygdala. J Neurosci Res 86:411-421. CrossRef Medline

Kumar S, Peña LA, de Vellis J (1993) CNS glial cells express neurotrophin receptors whose levels are regulated by NGF. Brain Res Mol Brain Res 17:163-168. Medline

Li C, Dabrowska J, Hazra R, Rainnie DG (2011) Synergistic activation of dopamine D1 and TrkB receptors mediate gain control of synaptic plasticity in the basolateral amygdala. PLoS One 6:e26065. CrossRef Medline

Li YX, Xu Y, Ju D, Lester HA, Davidson N, Schuman EM (1998) Expression of a dominant-negative TrkB receptor, $\mathrm{T} 1$, reveals a requirement for presynaptic signaling in BDNF-induced synaptic potentiation in cultured hippocampal neurons. Proc Natl Acad Sci U S A 95:10884-10889. Medline

Lonsdorf TB, Weike AI, Golkar A, Schalling M, Hamm AO, Ohman A (2010) Amygdala-dependent fear conditioning in humans is modulated by the BDNFval66met polymorphism. Behav Neurosci 124:9-15. CrossRef Medline

Lu L, Dempsey J, Liu SY, Bossert JM, Shaham Y (2004) A single infusion of brain-derived neurotrophic factor into the ventral tegmental area induces long-lasting potentiation of cocaine seeking after withdrawal. J Neurosci 24:1604-1611. CrossRef Medline

Meis S, Endres T, Lessmann V (2012) Postsynaptic BDNF signaling regulates long-term potentiation at thalamo-amygdala afferents. J Physiol 590: 193-208. CrossRef Medline

Musumeci G, Sciarretta C, Rodríguez-Moreno A, Al Banchaabouchi M, Negrete-Díaz V, Costanzi M, Berno V, Egorov AV, von Bohlen Und Halbach O, Cestari V, Delgado-García JM, Minichiello L (2009) TrkB modulates fear learning and amygdalar synaptic plasticity by specific docking sites. J Neurosci 29:10131-10143. CrossRef Medline

Offenhäuser N, Muzio V, Biffo S (2002) BDNF binding to truncated trkB.T1 does not affect gene expression. Neuroreport 13:1189-1193. Medline

Ou LC, Gean PW (2006) Regulation of amygdala-dependent learning by brain-derived neurotrophic factor is mediated by extracellular signalregulated kinase and phosphatidylinositol-3-kinase. Neuropsychopharmacology 31:287-296. CrossRef Medline

Pang PT, Teng HK, Zaitsev E, Woo NT, Sakata K, Zhen S, Teng KK, Yung WH, Hempstead BL, Lu B (2004) Cleavage of proBDNF by tPA/plasmin is essential for long-term hippocampal plasticity. Science 306:487-491. Medline

Paxinos G, Franklin K (2001) The mouse brain in stereotaxic coordinates. New York: Academic. 
Rattiner LM, Davis M, French CT, Ressler KJ (2004) Brain-derived neurotrophic factor and tyrosine kinase receptor $\mathrm{B}$ involvement in amygdala-dependent fear conditioning. J Neurosci 24:4796-4806. CrossRef Medline

Rattiner LM, Davis M, Ressler KJ (2005) Brain-derived neurotrophic factor in amygdala-dependent learning. Neuroscientist 11:323-333. CrossRef Medline

Ressler KJ, Paschall G, Zhou XL, Davis M (2002) Regulation of synaptic plasticity genes during consolidation of fear conditioning. J Neurosci 22: 7892-7902. Medline

Rogan MT, Stäubli UV, LeDoux JE (1997) Fear conditioning induces associative long-term potentiation in the amygdala. Nature 390:604-607. CrossRef Medline
Soliman F, Glatt CE, Bath KG, Levita L, Jones RM, Pattwell SS, Jing D, Tottenham N, Amso D, Somerville LH, Voss HU, Glover G, Ballon DJ, Liston C, Teslovich T, Van Kempen T, Lee FS, Casey BJ (2010) A genetic variant BDNF polymorphism alters extinction learning in both mouse and human. Science 327:863-866. CrossRef Medline

van Wingen G, Rijpkema M, Franke B, van Eijndhoven P, Tendolkar I, Verkes RJ, Buitelaar J, Fernández G (2010) The brain-derived neurotrophic factor Val66Met polymorphism affects memory formation and retrieval of biologically salient stimuli. Neuroimage 50:12121218. CrossRef Medline

Zhou XF, Parada LF, Soppet D, Rush RA (1993) Distribution of trkB tyrosine kinase immunoreactivity in the rat central nervous system. Brain Res 622:63-70. CrossRef Medline 